Sādhanā Vol. 40, Part 3, May 2015, pp. 835-849. (C) Indian Academy of Sciences

\title{
Mixed convection in a baffled grooved channel
}

\author{
AAYUSH K SHARMA ${ }^{1}$, PALLAB S MAHAPATRA ${ }^{1,2}$, \\ NIRMAL K MANNA $^{1, *}$ and KOUSHIK GHOSH ${ }^{1}$ \\ ${ }^{1}$ Department of Mechanical Engineering, Jadavpur University, \\ Kolkata 700 032, India \\ ${ }^{2}$ Department of Applied Mechanics, Indian Institute of Technology Madras, \\ Chennai 600 036, India \\ e-mail: nirmalkmannaju@gmail.com
}

MS received 16 May 2014; revised 19 October 2014; accepted 06 November 2014

\begin{abstract}
In the present numerical work, flow structure and heat transfer characteristics are investigated in a baffled grooved channel, differentially heated from the sides. The baffle is placed vertically downward from the top wall of grooved channel geometry, with the motive of diverting outside forced flow towards the inside of the square cavity. In-house CFD code based on finite volume method has been used to solve the $2 \mathrm{D}$ equations of continuity, momentum and energy. The effect of change in baffle position and height is investigated in the range of Richardson numbers 0.1 to 10. For the present study, external flow from both left and right of the grooved channel are considered. A remarkable enhancement of heat transfer is observed in presence of baffle. The study has also pointed out that for optimal performance, the position and height of the baffle need to be adjusted depending on the direction of external flow.
\end{abstract}

Keywords. Heat transfer; grooved channel; mixed convection; Richardson number; baffle.

\section{Introduction}

The need for effective cooling in the electronic industry has put a limitation on the application of conventional cooling methods like natural convection. This is one of the main reasons that mixed convection or combined forced and free convection has gained popularity over the years and would continue to do so with the size of all electronic devices shrinking drastically every day. Not only in the electronic industry but also in nuclear, solar, bio-medical are some of the diverse fields that employ mixed convection. Thus, its study is of paramount importance and today the focus is more on different techniques for enhancing heat transfer in mixed convective flow rather than employing simple mixed convective flow.

In electronic devices, there exist channels that often have protruding or flush mounted heaters. Du et al (1998) reviewed some literature in regard to the study of flush mounted heaters in channels undergoing mixed convection. The problem geometry in (How \& Hsu 1998) was that of

*For correspondence 
a square enclosure having a constant-flux heat source in the left vertical wall with a top opening on the same side and exit on the opposite side. A conducting baffle acting as a divider was placed either on the top wall or in the bottom wall. Hsu \& How (1999) investigated the problem of mixed convection in which the geometry and wall temperature conditions were similar to that of (How \& Hsu 1998) but it had a square heat conducting body located within the enclosure, unlike a baffle on the wall as in (How \& Hsu 1998). El-din (2002) investigated mixed convection in a vertical channel divided into two passages by means of a conductive baffle. Previous studies on mixed convection for U-shaped open cavities have been extensively reviewed by Manca et al (2003, 2008). A numerical investigation was carried out by Singh \& Sharif (2003), where a rectangular cavity with differentially heated side walls for different positions of inlet and outlet openings for the forced air and also different wall temperature conditions either hot or cold was considered. A cavity having finite length slots midway at the two vertical walls (left and right) and a constant heat flux source located on the left vertical wall with all other walls being perfectly insulated was considered by Raji et al (2008). A ventilated rectangular partitioned cavity was the geometry considered by Bahlaoui et al (2009) in which combined effect of mixed convection and radiation was investigated.

The application of baffles in channel or cavity has once again received considerable interest over the past few years. Chang \& Shiau (2005) investigated the effect of pulsating flow in a vertical open channel having a horizontal thin baffle at the right wall and a finite length of left wall heated by a constant heat flux. Three Baffles from the view point of aiding mixing process in a micro-mixer was implemented in Chung et al (2008). The dependence of mixing efficiency on baffle height and Reynolds number was investigated in this study.

Numerical studies on a ventilated cavity having a central heater near the inlet, at the lower left wall and having exit at the upper right wall was studied by Radhakrishnan et al (2009). Here, the effect of a baffle in increasing heat transfer was investigated, also the best position of the baffle among bottom, left, right and top was found in which heat transfer rate was enhanced by $50 \%$ as compared to the case of no-baffle. Asif et al (2011) also numerically studied ventilated cavity but here three isothermally heated baffles were placed alternately in the left and right walls. Horizontal Channel with two diamond-shaped baffles placed on the lower and upper walls in a staggered array was the problem geometry considered by Sripattanapipat \& Promvonge (2009). A numerical and experimental study on z-shaped baffles in the turbulent regime was conducted by Sriromreun et al (2012).

The above review of literature highlights the importance of study on mixed convection in a cavity or a channel as shown by Singh \& Sharif (2003): Manca et al (2003, 2008). The concept of using a baffle or a divider is very old and previous studies like How \& Hsu (1998) investigated the effect of change in baffle height and location on heat transfer in such geometries. However, over the few years, there has been a regained interest to the use of baffles in geometries. Recent studies in mixed convection in cavities or channels with baffles have different applications like in Chung et al (2008), where mixing was the prime objective. Still, most of the studies had the prime objective of increasing heat transfer when employing baffles. Studies by Radhakrishnan et al (2009), Asif et al (2011) dealt with the effect of a baffle in a ventilated cavity whereas Sripattanapipat \& Promvonge (2009); Sriromreun et al (2012) dealt with the effect of different shapes of the baffles in simple channels.

The present numerical study is an effort to analyse primarily flow and heat transfer in a differentially heated cavity lying at the bottom of a channel, similar to the geometry considered by Rahman et al $(2011,2012)$ but unlike the latter, here a thin adiabatic baffle at the top wall is present. The objective of placing a baffle is to enhance heat transfer by diverting forced flow from the channel to the square cavity at the bottom. Most of the previous studies, where baffles 
have been employed, have mostly focussed on ventilated cavities (Radhakrishnan et al 2009; Asif et al 2011) as their geometry. In the present study, a range of Richardson number $\mathrm{Ri}=0.1$ to 10 and different $\operatorname{Re}$ (10 and 200), are considered. Along with this the location and height of the baffle on the top wall is varied. The results of the same are compared to the case of without baffle-grooved channel geometry, in order to show the heat transfer enhancement achieved by the use of baffle in the grooved channel.

\section{Problem definition and numerical procedures}

The schematic diagram of the physical system is depicted in figure 1. Here, in figure 1a, a simple grooved channel is shown while in figure $1 \mathrm{~b}$, a baffled grooved channel is shown. Except the portion of isothermal hot and cold walls (left and right vertical walls of square cavity, forming the grooved channel), the rest of all the walls along with the baffle are considered to be adiabatic. The square cavity of the grooved channel has a dimension of ' $0.5 \mathrm{~L}$ ' while the entire geometry is ' $\mathrm{L} \times \mathrm{L}$ ', aspect ratio of 1 . A baffle of thickness ' $0.04 \mathrm{~L}$ ' with height ' $\mathrm{H}$ ', which was varied from ' 0.25 to 0.80 ', is placed at the top wall of the grooved channel. The baffle location was varied at three different locations; one near the hot wall or baffle at left, one in the centre of the geometry (as shown in figure 1b) and one near the cold wall or baffle at right condition.

The numerical simulation is based on the assumption that the temperature difference between the active walls is not very high such that Boussinesq approximation is valid. The flow is considered to be incompressible, laminar and two-dimensional. The transport properties of the fluid are taken constant and the effect of viscous dissipation is neglected.

Based on these assumptions, dimensionless form of governing equations for conservation of mass, momentum and energy becomes

$$
\begin{gathered}
\frac{\partial U}{\partial X}+\frac{\partial V}{\partial Y}=0 \\
\frac{\partial U}{\partial \tau}+U \frac{\partial U}{\partial X}+V \frac{\partial U}{\partial Y}=-\frac{\partial P}{\partial X}+\frac{1}{\operatorname{Re}}\left(\frac{\partial^{2} U}{\partial X^{2}}+\frac{\partial^{2} U}{\partial Y^{2}}\right),
\end{gathered}
$$

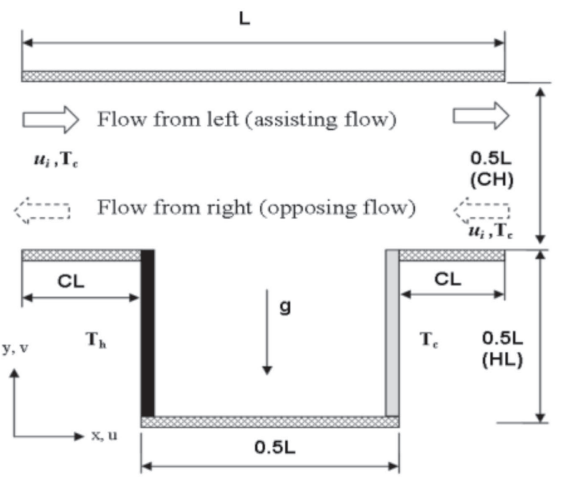

(a) without baffle

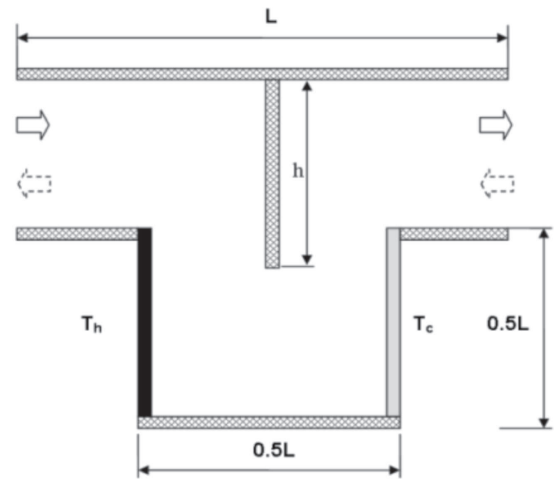

(b) with baffle

Figure 1. Physical description of mixed convection in grooved channel. 


$$
\begin{gathered}
\frac{\partial V}{\partial \tau}+U \frac{\partial V}{\partial X}+V \frac{\partial V}{\partial Y}=-\frac{\partial P}{\partial Y}+\frac{1}{\operatorname{Re}}\left(\frac{\partial^{2} V}{\partial X^{2}}+\frac{\partial^{2} V}{\partial Y^{2}}\right)+\operatorname{Ri} \theta, \\
\frac{\partial \theta}{\partial \tau}+U \frac{\partial \theta}{\partial X}+V \frac{\partial \theta}{\partial Y}=\frac{1}{\operatorname{RePr}}\left(\frac{\partial^{2} \theta}{\partial X^{2}}+\frac{\partial^{2} \theta}{\partial Y^{2}}\right) .
\end{gathered}
$$

The non-dimensionalisation is carried out on the basis of heater length, thermal diffusivity of fluid, temperature difference between hot and cold heaters as detailed below.

$$
\begin{aligned}
X & =\frac{x}{L}, Y=\frac{y}{L}, U=\frac{u}{u_{i}}, V=\frac{v}{u_{i}}, \\
\theta & =\frac{T-T_{c}}{T_{h}-T_{c}}, \tau=\frac{t \alpha}{L^{2}}, P=\frac{p-p_{a t m}}{\rho u_{i}^{2}} .
\end{aligned}
$$

And dimensionless numbers like Re, Pr, Ri and Gr are

$$
\operatorname{Re}=\frac{u_{i} L}{v} ; \operatorname{Pr}=\frac{v}{\alpha} ; \mathrm{Gr}=\frac{g \beta\left(T_{h}-T_{c}\right) L^{3}}{v^{2}} ; \mathrm{Ri}=\frac{\mathrm{Gr}}{\mathrm{Re}^{2}} .
$$

The boundary conditions for above mentioned Eqs. (1-4) are detailed below:

(i) at all walls $\mathrm{U}=\mathrm{V}=0$;

(ii) at inlet (either ways-rightwards or leftwards), $U=U_{i}= \pm 1$ and $\mathrm{V}=0$

(iii) at outlet constant pressure boundary condition, $P=0$

(iv) at inlet and cold wall, $\theta=0$; at hot wall, $\theta=1$

(v) at adiabatic walls, flow outlet and baffle, $\partial \theta / \partial n=0 ; n$ indicates normal direction.

\section{Nusselt Number}

The average Nusselt numbers at the hot wall or left wall is defined as

$$
N u_{a v g} \mathrm{~L}=\left|\frac{1}{\varepsilon} \int_{0}^{\varepsilon}\left[\frac{\partial \theta}{\partial X}\right]_{X=0.5} d Y\right|
$$

with $\varepsilon$, denoting the non-dimensional length of the heater or active wall.

$$
\varepsilon=\frac{H L}{L}=0.5
$$

The numerical solution of the governing equations is obtained by means of finite volume method (FVM) discretization and SIMPLE algorithm (Patankar 1980), ADI sweep and TDMA algorithm. The maximum value of mass defect was chosen to be less than $10^{-8}$ for the convergence of solutions. Time step independent study was carried out in order to determine suitable time-step for the problem. The code was run in transient mode with 3 different time-step sizes of $10^{-2}, 10^{-3}$ and $10^{-4}$, respectively. The results of $\mathrm{Nu}_{\mathrm{avg}}$ against $\mathrm{Ri}$ showed little variation for the three different time-step sizes and time-step size of $10^{-3}$ was chosen in the present work. Similarly, for grid independent study three different grid sizes $75 \times 50,100 \times 100$ and $150 \times$ 200 (width $\times$ height) were tested by plotting $\mathrm{Nu}_{\mathrm{avg}}$, obtained from each grid size, with $\mathrm{Ri}$. It was found that maximum error on the average Nusselt number was within $1 \%$ between the grid sizes of $100 \times 100$ and $150 \times 200$. Hence, for the present problem time step and grid size were selected as $10^{-3}$ and $100 \times 100$, respectively. 


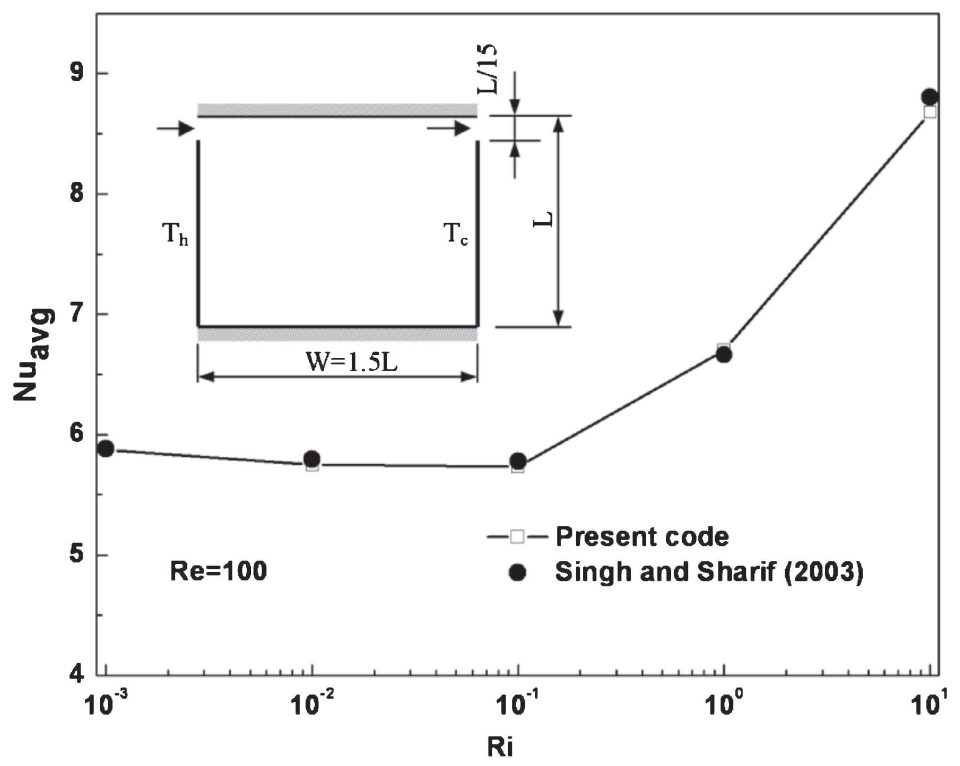

Figure 2. Validation study for mixed convection.

For natural convection, the code was validated against the benchmark results by Davis (1983) whose details are presented elsewhere by Mahapatra et al (2013). The code agrees with the benchmark results for stream function and Nusselt number with maximum error of 3.8 and $0.5 \%$, respectively. For forced convection, the code was validated against a conventional case of forced convection in fully developed internal laminar pipe flow. The standard result of $\mathrm{Nu}=3.66$ obtained confirmed the code's validation in forced convection regime too. In addition, here validation on mixed convection has also been incorporated, considering the work of Singh \& Sharif (2003) as presented in figure 2. For this validation, left-top inflow and right-top outflow configuration as marked 'A' in figure 1 of Singh \& Sharif (2003) also shown in the inset of figure 2 of present work is taken for $\mathrm{Re}=100$. The results presented in figure shows an excellent agreement between the two results. The maximum error obtained between the two results is within $1 \%$ for different Ri.

\section{Results and discussion}

The present study has been carried out in mixed convection regime where Ri varies from 0.1 to 10 at two different Re, 10 and 200. Along with this, two different external flow conditions are considered-flow from left and flow from right. In the following section, steady results have been shown which have been achieved by transient-time stepping method. First streamline and isotherm contours are discussed with the location of baffle varying in three different positions within the geometry-one near the left or hot wall referred as baffle left condition, then centre referred as baffle centre and one near the right or cold wall referred as baffle right condition. The effect of baffle size is also analysed by varying baffle length from ' 0.25 to 0.80 '.

Following this section, the average Nusselt plots are discussed, in comparison to without baffle condition, to bring about heat transfer enhancement, if any, for insertion of baffle. In order to verify the effect of channel length and height for the grooved channel a study was initially carried 
out and the results are presented in figure 3 . For all the cases presented in figure 3 the baffle height is $50 \%$ of the channel height $(\mathrm{CH})$ and baffle is always placed at the centre of the enclosure. From the results, it can be observed that the channel length (CL) increases from 0.25 to 0.75 does not provide major change in significant parameters, like for example, $\mathrm{Nu}_{\mathrm{avg}}$ (Nusselt number averaged over the hot wall), with change being less than $1 \%$. For the case of change in channel height $(\mathrm{CH})$ from 0.25 to 0.75 , the change in $\mathrm{Nu}_{\text {avg }}$ was within $2 \%$. Thus in the present problem of mixed convection in the grooved channel, height and length of the channel were fixed as 0.50 and 0.25 , respectively.

\subsection{Streamline and isotherm contours-external flow from left}

Figure 4 shows contours of streamlines at $\mathrm{Re}=200$ for external flow from left condition, at differnt location of the baffle (left, centre and right) with baffle size varying from 0.25 to 0.80 . It is observed that for low baffle height $(\mathrm{H}=0.25)$ at all different locations of baffle, a circulating

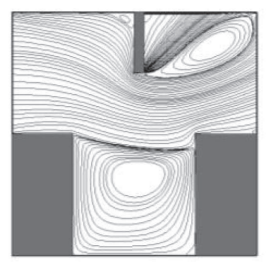

(i) $\mathrm{CL}=0.25$, $\mathrm{Nu}_{\mathrm{avg}}=4.817$

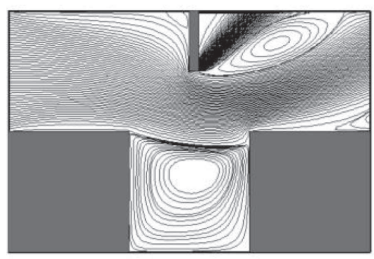

(ii) $\mathrm{CL}=0.50$, $\mathrm{Nu}_{\mathrm{avg}}=4.819$

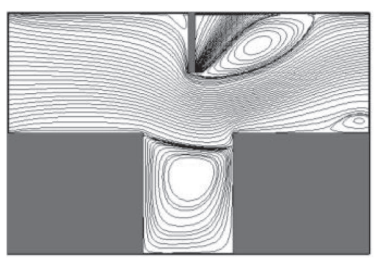

(iii) $\mathrm{CL}=0.75$, $\mathrm{Nu}_{\mathrm{avg}}=4.814$

(a) Effect of channel length (CL)

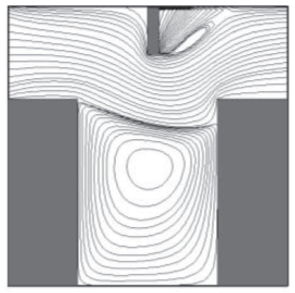

(i) $\mathrm{CH}=0.25$, $\mathrm{Nu}_{\mathrm{avg}}=4.763$

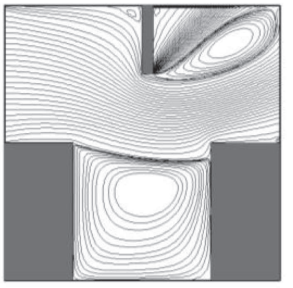

(ii) $\mathrm{CH}=0.50$, $\mathrm{Nu}_{\mathrm{avg}}=4.817$

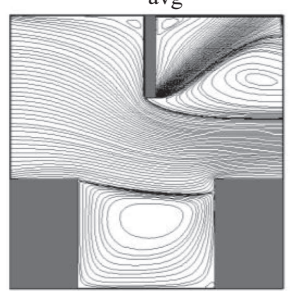

(iii) $\mathrm{CH}=0.75$, $\mathrm{Nu}_{\mathrm{avg}}=4.847$

(b) Effect of channel height $(\mathrm{CH})$

Figure 3. Comparison of $\mathrm{Nu}_{\text {avg }}$ at $\mathrm{Ri}=1, \mathrm{Re}=200$ for external flow from left condition with baffle height as 0.25 . 

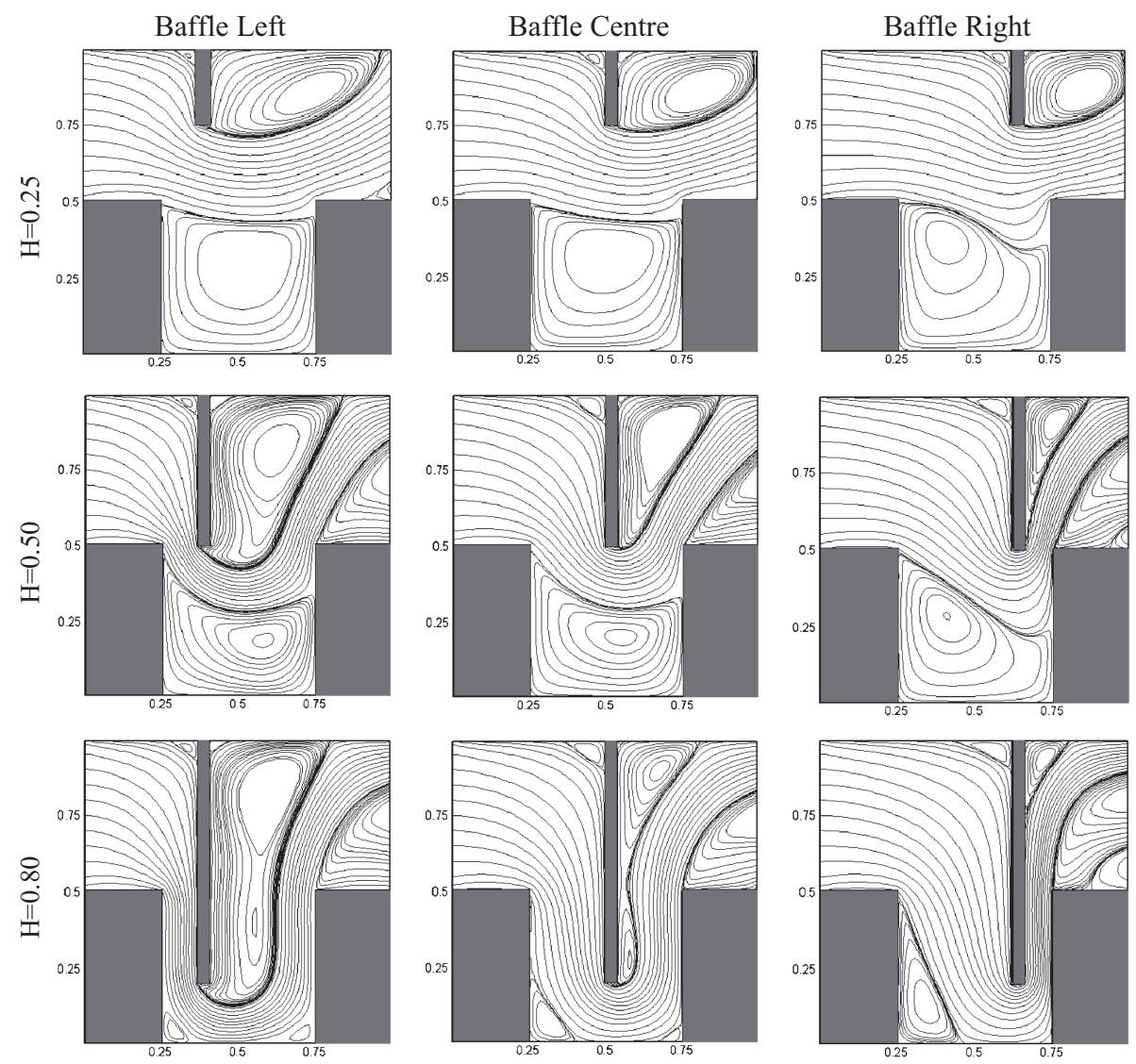

Figure 4. Streamlines for flow from left condition at $\mathrm{Re}=200, \mathrm{Ri}=1$.

cell encompassing nearly the entire square cavity is formed. Due to the baffle, a second circulating cell is observed behind it, due to creation of an isolated region. With increase in baffle height to 0.50 , the external flow is forced to disturb the circulating cell formed in the square cavity. The location of the baffle plays an important role in the shape of the circulating cell formed in the square cavity as well as the one behind the baffle. For the baffle close to the hot wall (left position) when baffle height is increased to 0.80 , the external flow is forced to travel parallel along the heater.

The introduction of baffle enables the external flow to carry away substantial amount of heat through the cavity, which is clearly represented in the heat transfer enhancement plots, to be discussed later. For the centre and the right position when $\mathrm{H}=0.80$, small circulating cells are still formed in the lower bottom corners of the square cavity. With increase in baffle height, the external flow is able to break the formation of circulating cell that exists otherwise throughout the square cavity of the grooved channel, at lower values of $\mathrm{H}$.

The isotherm contours (as shown in figure 5) helps to visualize the temperature distribution in the geometry. It is noticed that at $\mathrm{H}=0.25$ for baffle left condition high valued contours are more distributed in the entire square cavity. However, with increase in height as the external flow 

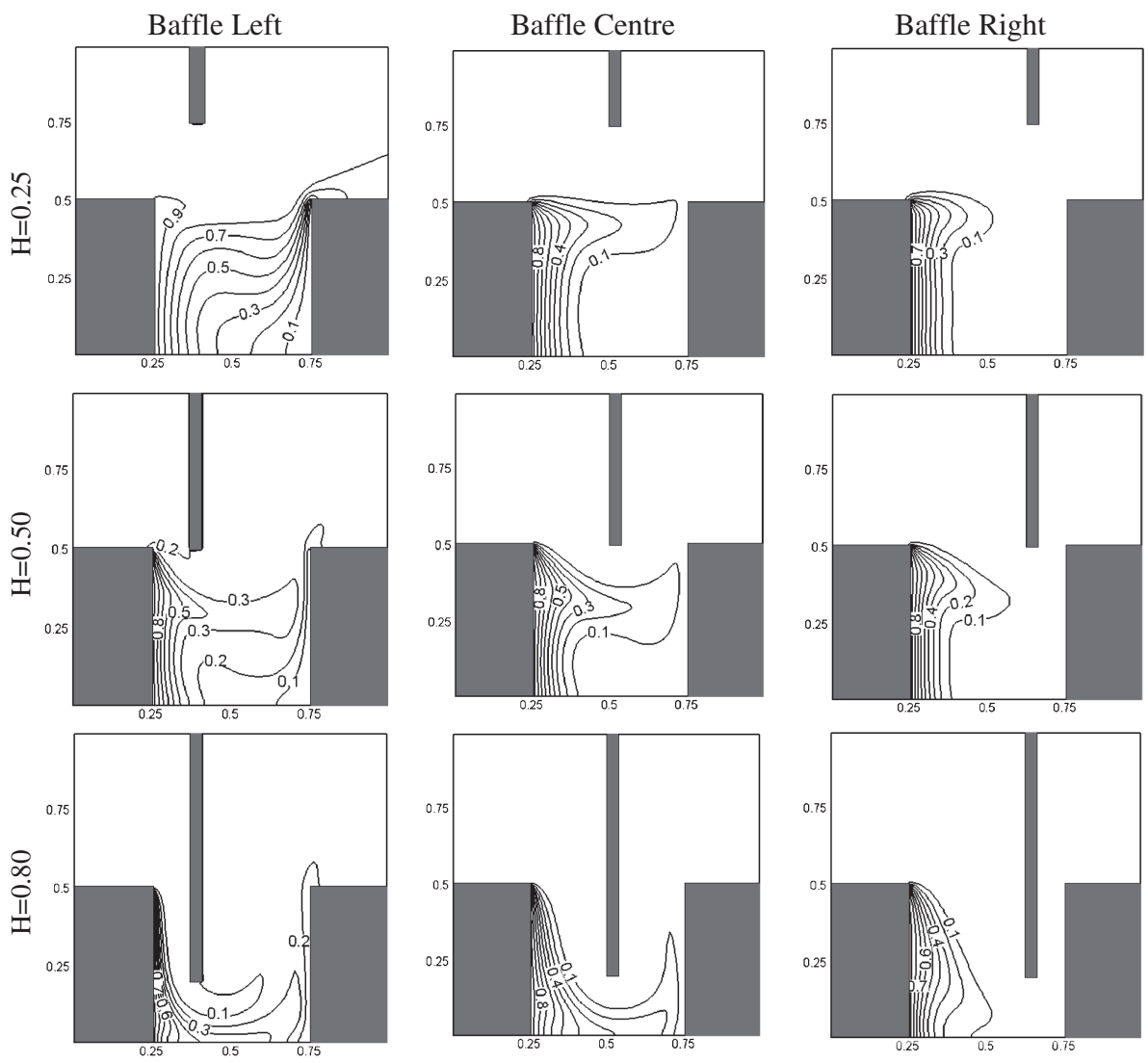

Figure 5. Isotherms for flow from left condition at $\mathrm{Re}=200, \mathrm{Ri}=1$.

is now able to disturb the circulating cell in the cavity more prominently, high valued contours are limited to regions near the hot wall while low valued contours dominate the other regions of the cavity.

For baffle centre condition at low baffle height $(\mathrm{H}=0.25)$ itself the high valued contours get limited to hot wall regions, while previously for baffle left condition a more uniformly distributed contours were observed. With increase in baffle height $(\mathrm{H}=0.50$ onwards $)$ as the influence of external flow increases, low valued contours dominate a majority of the cavity. For baffle right condition the isotherm contours for all baffle heights $(0.25,0.50$ and 0.80$)$ show high valued contours being limited to regions near the hot wall with low valued dominating major regions of the cavity of grooved channel.

\subsection{Streamline and isotherm contours-external flow from right}

Figure 6 shows the streamline contours at $\mathrm{Re}=200$ for $\mathrm{Ri}=1$, with external flow being from right. It is observed that at lower value of baffle height (0.25), at all different locations of the baffle-left, centre and right, two circulating cells exist in the square cavity of the grooved channel, along with the one that exists behind the baffle as a result of an isolated zone created because 

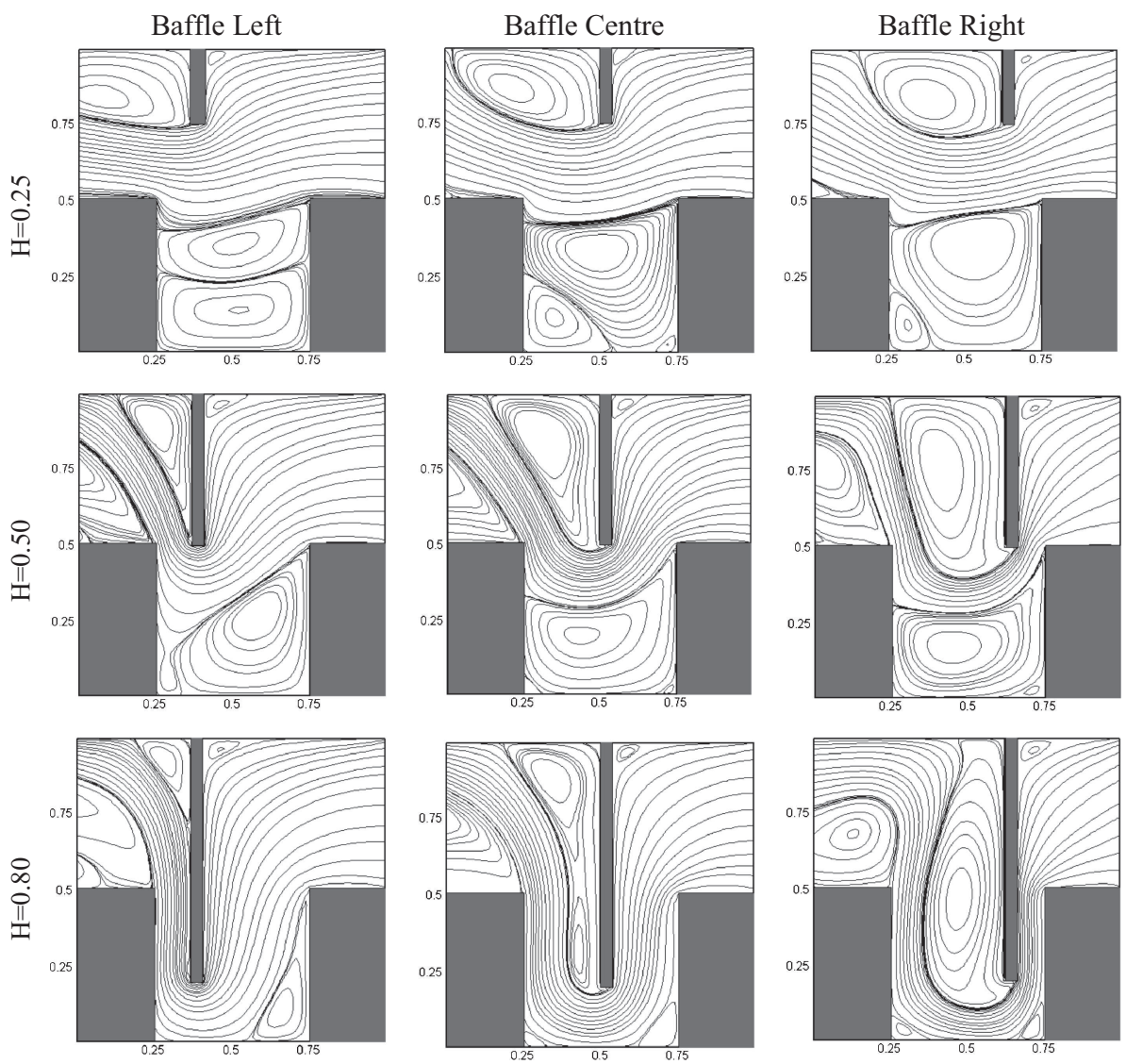

Figure 6. Streamlines and isotherms for flow from right condition at $\mathrm{Re}=200, \mathrm{Ri}=1$.

of the baffle. When baffle height is increased to 0.50 , for all locations of the baffle- closer to the hot wall (left), at the centre and closer to the cold wall (right), the external flow impinges the hot wall and pushes the circulating cell formed in the square cavity of the grooved channel. When baffle height is increased to $\mathrm{H}=0.80$, the external flow is forced to enter the square cavity. For $\mathrm{H}>0.25$ the external flow is guided along the baffle and it disturbs the circulating cells inside the square cavity. As such, only one circulating cell is observed and for higher baffle height the circulating cell is moved towards the opposite corner. However, the length of the circulating cell formed behind the baffle increases with increase in baffle height.

The isotherm contours (as shown in figure 7) show that in the square cavity a distributed isotherm contours exist only for baffle left condition at $\mathrm{H}=0.25$. Except this condition, majority of the high valued isotherm contours get restricted to regions near the hot wall, which is a result of the external flow influence on circulating cell of cavity which increases with increase in baffle height values for all baffle locations. At high values of baffle height $(H=0.80)$ the influence of external flow is most prominent in the square cavity for all baffle locations as evident form streamline contours. The isotherm contours show low valued contours extending in the left end of the channel passage while the high valued contours mainly adhere to the regions near the hot wall. 

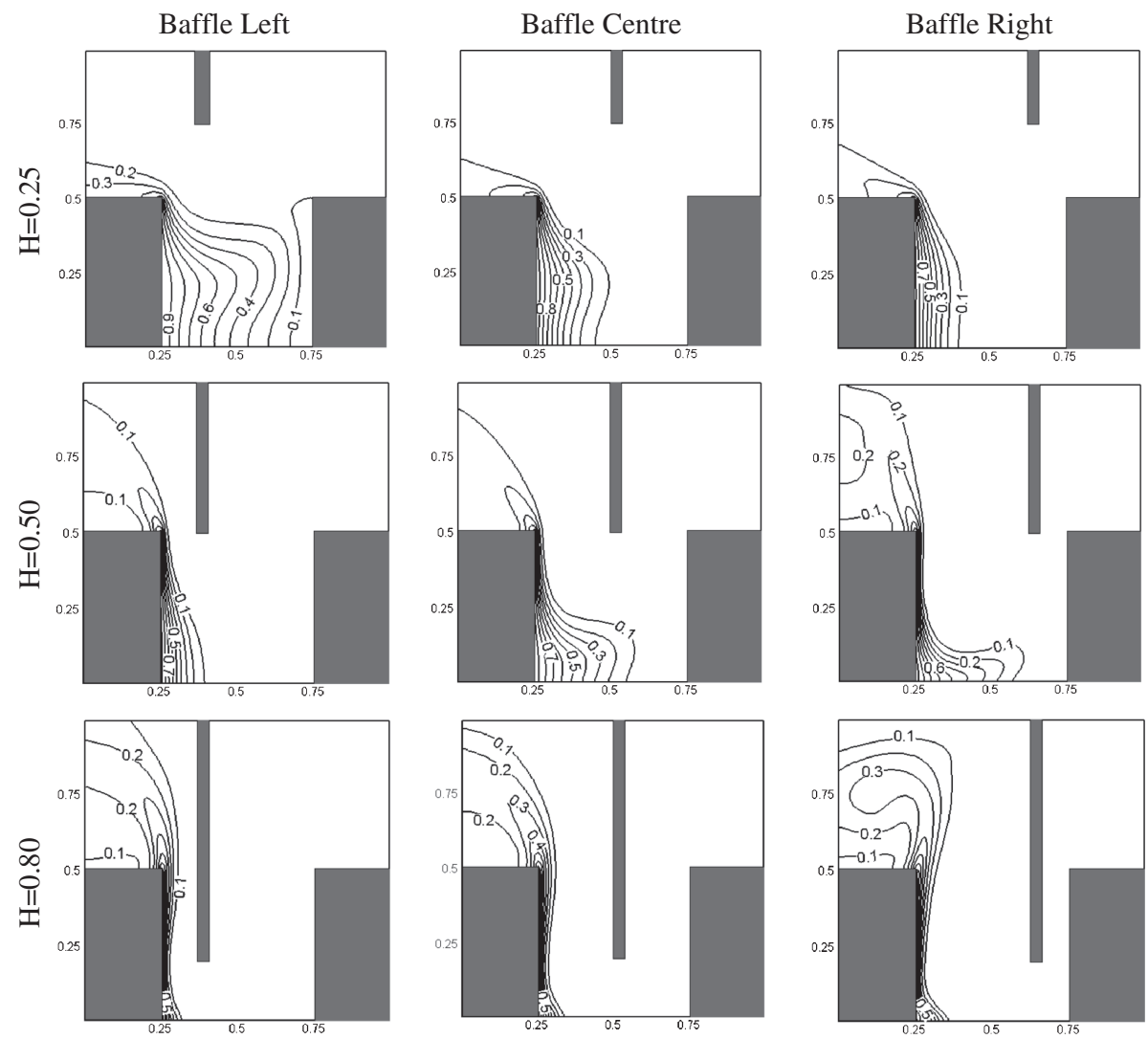

Figure 7. Isotherms for flow from right condition at $\mathrm{Re}=200, \mathrm{Ri}=1$.

\subsection{Heat transfer enhancement, $\eta$}

Employing a baffle as oppose to a plain grooved channel for mixed convection is only justified, if there is an appreciable heat transfer enhancement, with the use of a baffle. The contours of streamlines reveal the flow pattern for the baffled grooved channel. Different locations of the baffle - left, centre and right are considered along with different baffle heights (0.25 to 0.80). The succeeding section discusses the heat transfer enhancement for such geometries, which would justify their applicability in mixed convection regime for different practical applications and devices.

A parameter $\eta$, referred as heat transfer enhancement parameter is introduced. It is defined as average Nusselt number with baffle to that without baffle. Here, the average Nusselt number $\left(\mathrm{Nu}_{\mathrm{avgL}}\right)$ is defined as the local Nusselt number averaged over the hot or left wall. From the plots shown in figure 8 enhancement exists, only if $\eta$ lies above 1 . The plot helps to quantify the enhancement and also suggest suitable location and size of the baffle depending on the external flow direction to achieve the best heat transfer enhancement from the different considered variations of the baffled geometry.

It is observed that when external flow is from left, for $\mathrm{Ri}=0.1$ and 1 , the location of the baffle at center and right for all baffle heights considered $(0.25$ to 0.80$)$ there is a marginal heat transfer 

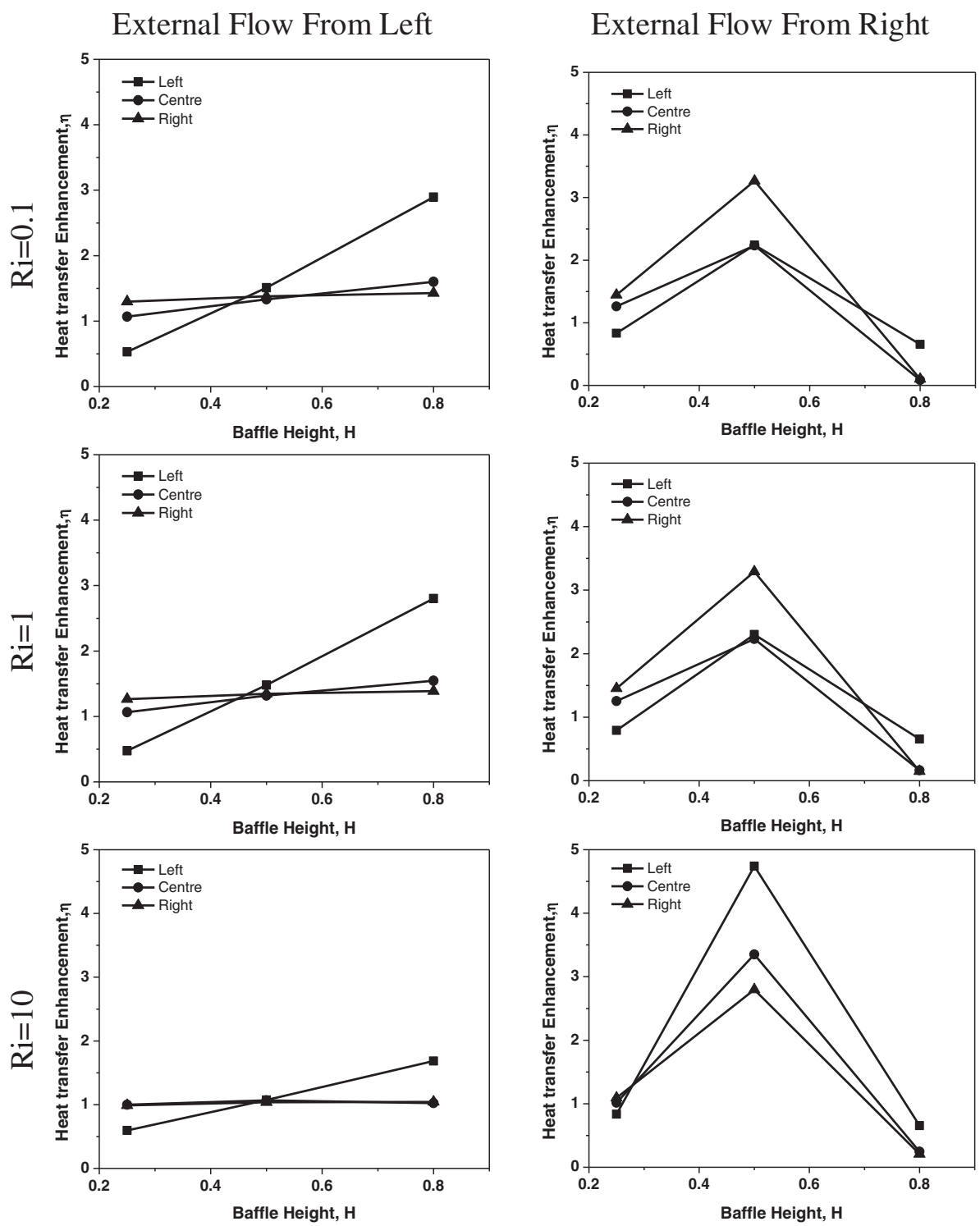

Figure 8. Heat transfer enhancement plots for flow from left and right condition at $\mathrm{Re}=200$ and at different Ri.

enhancement, depicted in figure 8 . For $\mathrm{Ri}=1$, there is however, no significant enhancement when baffle is kept at the right position.

For the case of baffle closer to the hot wall or left position, it is observed that at lower value of baffle height $(\mathrm{H}=0.25)$, no enhancement exists but with increase in $\mathrm{H}$ above 0.45 , enhancement is reported. This enhancement reported, for the baffle at left position, exists when beyond $\mathrm{H}=0.45$, where it is marginal, and becomes nearly twice, when $\mathrm{H}$ is 0.80 for $\mathrm{Ri}=0.1$ and 1 . For $\mathrm{Ri}=10$, lower enhancement at $\mathrm{H}=0.80$ for left position of baffle, exists which could primarily be due to increase in the role of natural convection as oppose to forced convection, as Ri 
is increasing. For the case of flow from right scenario, at $\mathrm{Ri}(\mathrm{Ri}=0.1,1)$ at lower value of baffle height $(0.25)$ heat transfer enhancement is observed as values of $\eta$ lie above 1 , for baffle located, closer to cold wall or right and at center. For baffle at left condition, for the same H, no enhancement exists, as value of $\eta$ is below 1 , for $\mathrm{Ri}=0.1-10$. Similarly, no enhancement exists when

\section{Streamlines}

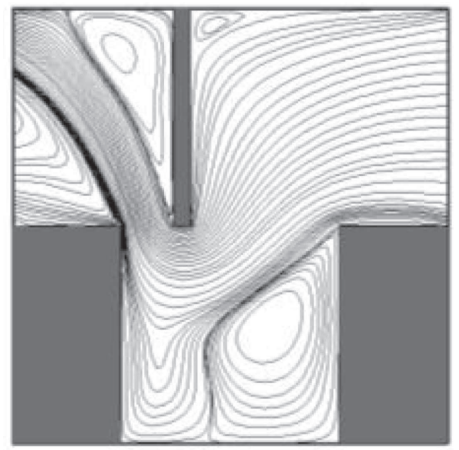

\section{Isotherms}

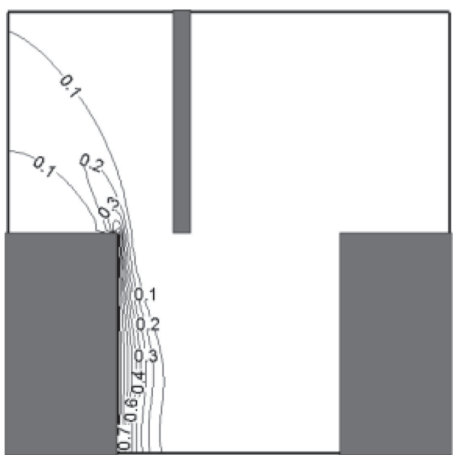

(a) Baffle Left
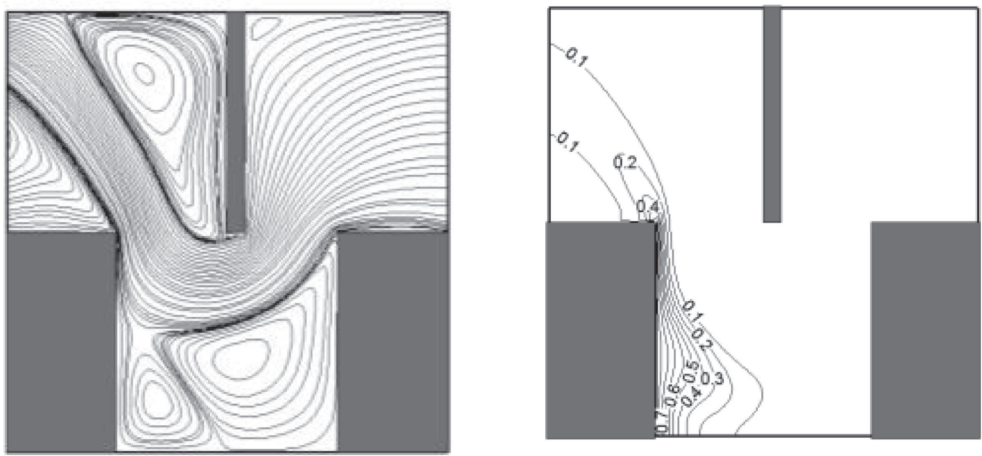

(b) Baffle Centre
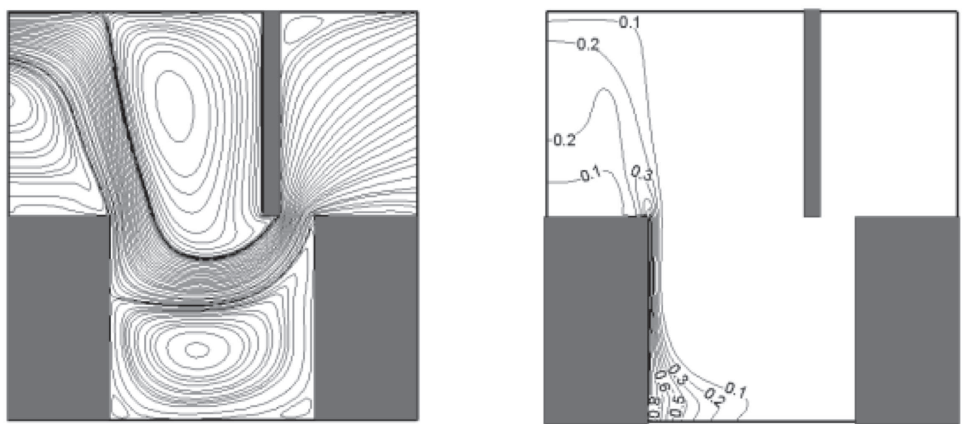

\section{(c) Baffle Right}

Figure 9. Streamline and Isotherm contours at $\mathrm{Ri}=10$ for $\mathrm{Re}=200$ with $\mathrm{H}=0.50$. 
baffle height, $\mathrm{H}=0.80$, for all values of $\mathrm{Ri}(0.1-10)$ and at all locations of the baffle considered. For flow from right condition, at $\mathrm{H}=0.50$, appreciable enhancement exists for all values of $\mathrm{Ri}$ and at all positions of the baffle-left, center and right. Here, majorly for baffle placed closer to the cold wall or at the right position, $\eta$ lies close to 3 , indicating nearly thrice the enhancement as compared to without baffle case. This is reported for the case when $\mathrm{Ri}=0.1$ and 1 . However, when $\mathrm{Ri}=10$, there is a significant increase in enhancement, $\eta$ being close to 5 , for the case when $\mathrm{H}=0.50$, for flow from left condition.

The contours of streamline along with isotherm contours shown in figure 9 helps to visualize this abrupt enhancement reported for baffle kept at left position when $\mathrm{Ri}=10$ and $\mathrm{H}=0.50$, for external flow from right condition. It can be inferred that here when the baffle is located at the left position, the external flow is forced to enter the square cavity entirely from the hot wall end and limit the circulating cell to the cold wall end. However, for baffle placed at the centre and at right the external flow does not influence the hot wall or heater end entirely. The isotherm contours for baffle left condition also show the contours to be parallel along the hot wall while for baffle centre and right condition the contours spread along the lower bottom half of the cavity which is a result of influence of external flow. Thus the reason for such high value of enhancement reported for baffle placed at left condition is the influence of external flow to carry substantial amount of heat unlike other baffle locations, shown by streamline and isotherm contours as in figure 9 . The contours of streamlines and isotherm have shown earlier, in figures (4-7) for external flow from left and right condition respectively, helps to justify the heat transfer enhancement findings of the present study.

The order of the pumping power for the present problem is $\sim q \Delta p$. Where, $q$ is the volume flow rate and $\Delta p$ is the pressure drop across the channel. The pressure drop can be estimated from the non-dimensional pressure drop obtained from the numerical solution as $\Delta p=\rho u_{i}^{2} \Delta P$. So, the pumping power is assessed in dimensionless form (dividing it by $q \rho u_{i}^{2}$ ) in this work, that yields non-dimensional pumping power equals dimensionless pressure drop. The dimensionless

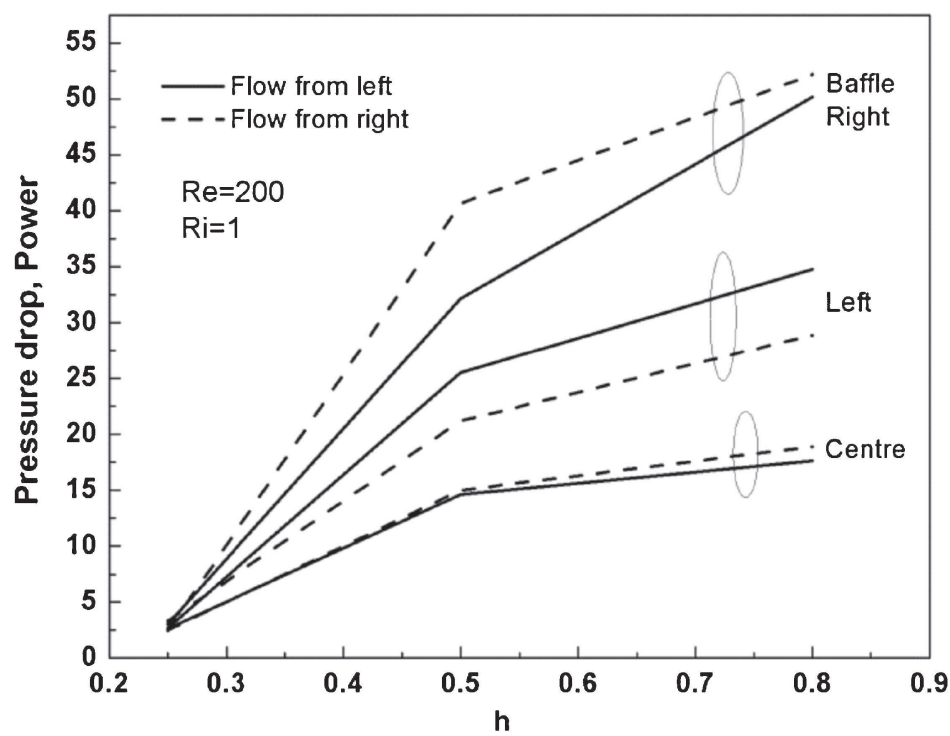

Figure 10. Non-dimensional pressure drop and pumping power for different baffle heights. 
pressure drop and pumping power for different baffle heights at $\mathrm{Re}=200$ and $\mathrm{Ri}=1$ is shown in figure 10. It is found that with the increase in baffle height for any baffle location and fluid flow direction, the pressure drop as well as pumping power increases. The pressure drop is maximum when the baffle is positioned at the right and flow is also from the right side of the channel. Therefore, it can be said that heat transfer will increase with the baffle height with the cost of more pumping power.

\section{Conclusions}

The present study reveals the following:

- For mixed convection, baffled grooved channel a superior alternative to plain grooved channel when heat transfer enhancement is the prime objective.

- For external flow from left condition, baffle location closer to hot wall preferable, only constrain is baffle height should be above 0.50 .

- For external flow from right condition, baffle with $\mathrm{H}=0.50$, located closer to cold right wall is preferable, when $\mathrm{Ri}=0.1-1$, for higher values of $\mathrm{Ri}(\mathrm{Ri}=10)$, baffle closer to hot left is wall preferred.

- For external flow from right condition increasing baffle height $\mathrm{H}$, beyond 0.50 significantly affects heat transfer enhancement, hence optimum height of baffle, should be around 0.50 to achieve maximum enhancement at any location (left, centre and right) of the baffle.

- Both pumping power and pressure drop are found to increase with the baffle height.

\section{Nomenclature}

CH Channel height

CL Channel length

Gr Grashof number

$g \quad$ Acceleration due to gravity

$h \quad$ Height of the baffle

$H \quad$ Non-dimensional baffle height (h/L)

$H L \quad$ Heater length

$L \quad$ Length of the grooved channel

$\mathrm{Nu} \quad$ Nusselt number

$p \quad$ Pressure

$P \quad$ Dimensionless pressure

Pr Prandtl number

Re Reynolds number

Ri Richardson number

t Time

$T$ Temperature

$T_{c} \quad$ Cold wall temperature

$T_{h} \quad$ Hot wall temperature

$u, v$ Velocity $u_{i} \quad$ Velocity at entry of grooved channel

$U, V$ Dimensionless velocities

$x, y \quad$ Cartesian coordinates

$X, Y$ Dimensionless Cartesian coordinates

\section{Greek symbols}

$\alpha \quad$ Thermal diffusivity

$\beta \quad$ Thermal expansion coefficient

$\varepsilon \quad$ Length of the heater or hot wall

$\eta \quad$ Heat tansfer enhancement parameter

$\theta \quad$ Non-dimensional temperature

$v \quad$ Kinematic viscosity

$\rho \quad$ Fluid density

$\tau \quad$ Dimensionless time

$\psi \quad$ Dimensionless stream function

\section{Subscripts}

avgL Averaged over left wall

atm Atmospheric

i Inlet 


\section{References}

Asif M R, Hossain M S and Hossain K A 2011 Heat Transfer in a rectangular enclosure with baffles. ARPN J. Eng. Appl. Sci. 6: 29-41

Bahlaoui A, Raji A, Hasnaoui M, Naïmi M, Makayssi T and Lamsaadi M 2009 Mixed convection cooling combined with surface radiation in a partitioned rectangular cavity. Energy Conv. Management 50: 626635

Chang T-S and Shiau Y-H 2005 Flow pulsation and baffles effects on the opposing mixed convection in a vertical channel. Inter. J. Heat Mass Transfer 48: 4190-4204

Chung C K, Wu C-Y and Shih T R 2008 Effect of baffle height and Reynolds number on fluid mixing. Microsyst. Technol. 14: 1317-1323

Davis G D V 1983 Natural convection of air in a square cavity: A bench mark numerical solution. Int. J. Numer. Methods Fluids 3: 249-264

Du S-Q, Bilgen E and Vasseur P 1998 Mixed convection heat transfer in open ended channels with protruding heaters. Heat Mass Transfer 34: 263-270

El-din M M S 2002 Effect of viscous dissipation on fully developed laminar mixed convection in a vertical double-passage channel. Int. J. Thermal Sci. 41: 253-259

How S-P and Hsu T-H 1998 Transient mixed convection in a partially divided enclosure. Computers Math. Applic. 36: 95-115

Hsu T H and How S P 1999 Mixed convection in an enclosure with a heat-conducting body. Acta Mechanica 133: 87-104

Mahapatra P S, De S, Ghosh K, Manna N K and Mukhopadhyay A 2013 Heat transfer enhancement and entropy generation in a square enclosure in the presence of adiabatic and isothermal blocks. Numer. Heat Transfer A 64: 577-596

Manca O, Nardini S, Khanafer K and Vafai K 2003 Effect of heated wall position on mixed convection in a channel with an open cavity. Numer. Heat Transfer A 43: 259-282

Manca O, Nardini S and Vafai K 2008 Experimental investigation of opposing mixed convection in a channel with an open cavity below. Exper. Heat Transfer 21: 99-114

Patankar S V 1980 Numerical heat transfer and fluid flow. New York: Hemisphere

Radhakrishnan T V, Joseph G, Balaji C and Venkateshan S P 2009 Effect of baffle on convective heat transfer from a heat generating element in a ventilated cavity. Heat Mass Transfer 45: 1069-1082

Rahman M M, Oztop H F, Rahman N A, Saidur R, Al-Salem Amin N, Mamun M A H and Ahsan A 2012 Computational analysis of mixed convection in a channel with a cavity heated from different sides. Int. Commun. Heat Mass Transfer 39: 78-84

Rahman M M, Parvin S, Saidur R and Rahim N A 2011 Magnetohydrodynamic mixed convection in a horizontal channel with an open cavity. Int. Commun. Heat Mass Transfer 38: 184-193

Raji A, Hasnaoui M and Bahlaoui A 2008 Numerical study of natural convection dominated heat transfer in a ventilated cavity: Case of forced flow playing simultaneous assisting and opposing roles. Int. J. Heat Fluid Flow 29: 1174-1181

Singh S and Sharif M A R 2003 Mixed convective cooling of a rectangular cavity with inlet and exit openings on differentially heated side walls. Numer. Heat Transfer A 44: 233-253

Sripattanapipat S and Promvonge P 2009 Numerical analysis of laminar heat transfer in a channel with diamond-shaped baffles. Int. Commun. Heat Mass Transfer 36: 32-38

Sriromreun P, Thianpong C and Promvonge P 2012 Experimental and numerical study on heat transfer enhancement in a channel with Z-shaped baffles. Int. Commun. Heat Mass Transfer 39: 945-952 